\title{
Stenting the Left Secondary Carina: 'A Fork in the Road'
}

\author{
Hervé Dutau ${ }^{\mathrm{a}}$ David P. Breen ${ }^{\mathrm{b}}$ \\ ${ }^{a}$ Thoracic Oncology, Pleural Diseases and Interventional Pulmonology Department, North University Hospital, \\ Marseille, France; ${ }^{\mathrm{b}}$ Interventional Respiratory Unit, Department of Respiratory Medicine, Galway University \\ Hospitals, Galway, Ireland
}

'Another turning point, a fork stuck in the road'; these are the first words of the song 'Time of your life' by Green Day, and they could easily summarize the ultimate challenge of airway stenting for interventional pulmonologists. The most difficult cases requiring stenting include diseases involving the main carina; however, these procedures are well established, and there are a number of stent options available including silicone, self-expandable and hybrid Y-stents [1-3]. The ultimate challenge is provided by disease beyond the main carina including the management of stenosis or obstruction at the right and left secondary carinae (RSC and LSC, respectively).

The anatomy of the secondary carina (SC) on both sides is more complex than that of the main carina. Indeed, both SC present with three branches of different diameters. On the right side, the upper lobar bronchus is almost perpendicular to the axis of the main stem bronchus-bronchus intermedius. On the left side, the main stem bronchus, the upper and lower lobar bronchi present a fork whose anatomical angle is quite similar to that of the main carina but with differing diameters of each stem. Therefore, the chosen stent has to conform to this peculiar anatomy.

In this issue of Respiration, Oki and Saka [4] report their experience of Y-stent placement in a group of 12 patients suffering from malignant conditions of the LSC and demonstrate that this procedure was technically fea-

\section{KARGER 125}

(c) 2015 S. Karger AG, Basel

0025-7931/15/0906-0441\$39.50/0

E-Mail karger@karger.com

www.karger.com/res sible and clinically beneficial to all patients in this cohort who were stented. In a previous paper, the same authors showed that stenting the RSC was better achieved using a dedicated silicone stent with a horizontal branch for the right upper lobe [5]. In fact, other authors have already published case reports [6-8] regarding stenting of the LSC both in malignant and benign conditions. All these reports have demonstrated that this procedure is feasible, although technically difficult.

Commercially produced silicone $\mathrm{Y}$-stents are available in 4 different diameters: $18 / 14 / 14,16 / 13 / 13,15 / 12 / 12$ and $14 / 10 / 10$. The first number represents the diameter of the main branch (in millimeters), while the latter two represent the diameters of the stent branches. The length of the main branch is $110 \mathrm{~mm}$, and the branches' lengths are $50 \mathrm{~mm}$. In routine interventional pulmonology practice, it is rare that an entire $\mathrm{Y}$-stent is placed as this would result in excessive covering of airway mucosa with subsequent mucous plugging or stent obstruction due to difficult secretion drainage. A silicone $\mathrm{Y}$-stent is always customized for the condition that is to be treated [2].

On-site customization is a significant advantage of silicone stents [9]. This can be performed without jeopardizing the mechanical properties of the silicone stents; a characteristic that is not shared by metallic stents.

Stenting the LSC implies the use of a small Y-stent $(14 / 10 / 10)$ that has to be customized on site. The main 
issue is the positioning of the branch that has to go in the left upper lobar (LUL) bronchus, and this has to be routinely cut short ( $<10 \mathrm{~mm}$ in general). The main challenges experienced with the left lower lobe (LLL) branch is the proximity of B6 (apical subsegment) and maintaining its function and drainage. In some cases, the function of B6 can be maintained by further stent customization by cutting an orifice in the stent as previously described (using a dedicated forceps) [9]. In contrast to the authors, we advocate a pulling-back technique if possible. This means that we insert the stent in the LLL bronchus and pull back the stent from its proximal edge. In these cases, the LUL limb is cut shorter than the LLL limb and therefore, the branch will insert into the LUL bronchus while the stent is being retracted proximally. When stenting the RSC, an alternative to the Oki stent [5] is to customize a Montgomery T-tube using a dedicated forceps. This stent is well designed for the anatomy of the RSC [10]. Its placement is similar to that of any other silicone stent.

Airway stenting is performed more frequently for malignant conditions, as seen in the paper by Oki and Saka [4]. However, stenting is much more challenging in benign conditions and is associated with greater complication rates primarily due to the predicted long life expec- tancy of these patients. In malignant disease, the patients generally die before significant stent-related complications occur. In benign conditions, the stent is usually a temporary intervention. However, it can occasionally be required for longer if the underlying condition persists, thus exposing the patient to stent-related complications. In our opinion, postsurgical anastomotic stricture is the most challenging endoscopic situation requiring stent placement. In lung transplantation, the surgical practice is to cut the donor bronchus as short as possible in order to reduce anastomotic complications [11]. Therefore, only one or two cartilaginous rings of the donor bronchus remain, and the bronchial anastomosis is very close to the LSC or RSC. If a stricture occurs at the left anastomotic stricture, placement of a Y-stent is often indicated [8].

Finally, cases of postbronchial reimplantation strictures from bronchoplastic lobectomies performed for malignancy provides an even greater challenge [12]. Indeed, these strictures can involve the anastomotic site and extend into the segmental bronchi of the reimplanted lobes. Currently, these strictures are often not amenable to stenting or would demand placement of stents that have not yet been developed for clinical use. However, this is a story for another day and, as yet, has to be written.

\section{References}

1 Freitag L, Tekolf E, Greschuchna D: Development of a new insertion technique and a new device for the placement of bifurcated airway stents. Surg Endosc 1994;8:1409-1411.

2 Dutau H, Toutblanc B, Lamb C, Seijo L: Use of the Dumon Y-stent in the management of malignant disease involving the carina: a retrospective review of 86 patients. Chest 2004; 126:951-958.

3 Gompelmann D, Eberhardt R, Schuhmann M, Heussel CP, Herth FJ: Self-expanding Y stents in the treatment of central airway stenosis: a retrospective analysis. Ther $\mathrm{Adv}$ Respir Dis 2013;7:255-263.

4 Oki M, Saka H: Silicone Y-stent placement on the secondary left carina. Respiration 2015; 90:493-498.

5 Oki M, Saka H: New dedicated bifurcated silicone stent placement for stenosis around the primary right carina. Chest 2013;144:450455.
6 Murgu SD, Colt HG: Silicone Y stent placement at secondary left carina for malignant central airway obstruction. J Thorac Cardiovasc Surg 2010;139:494-495.

7 Higuchi T, Shiraishi T, Hiratsuka M, Yanagisawa J, Iwasaki A: Successful treatment of bronchial anastomotic stenosis with modified Dumon Y-stent insertion in lung transplantation: report of a case. Surg Today 2011;41: 1302-1305.

-8 Lee HJ, Puchalski J, Sterman DH, Bhadra K, Kumar R, Gillespie CT, Haas AR: Secondary carina $\mathrm{Y}$-stent placement for post-lung-transplant bronchial stenosis. J Bronchology Interv Pulmonol 2012;19:109-114.

-9 Breen DP, Dutau H: On-site customization of silicone stents: towards optimal palliation of complex airway conditions. Respiration 2009; 77:447-453.
10 Lari SM, Gonin F, Colchen A: The management of bronchus intermedius complications after lung transplantation: a retrospective study. J Cardiothorac Surg 2012;20:7-8.

11 Dutau H, Vandemoortele T, Laroumagne S, Gomez C, Boussaud V, Cavailles A, Cellerin L, Colchen A, Degot T, Gonin F, Hermant C, Jougon J, Kessler R, Philit F, Pison C, Saint Raymond C, Wermert D, Astoul P, Thomas P, Reynaud-Gaubert M, Vergnon JM: A new endoscopic standardized grading system for macroscopic central airway complications following lung transplantation: the MDS classification. Eur J Cardiothorac Surg 2014; 45:e33-e38.

12 Bylicki O, Vandemoortele T, Orsini B, Laroumagne S, D'Journo XB, Astoul P, Thomas PA, Dutau $\mathrm{H}$ : Incidence and management of anastomotic complications after bronchial resection: a retrospective study. Ann Thorac Surg 2014;98:1961-1967. 